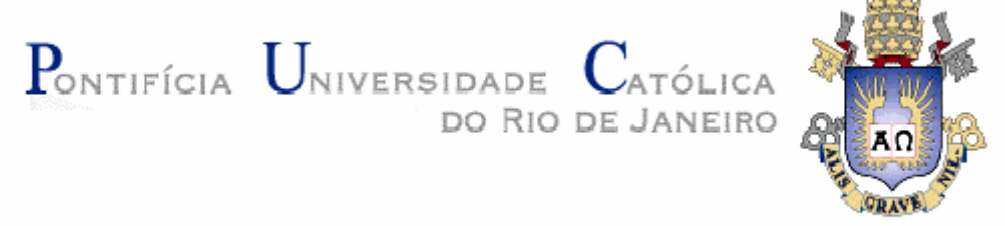

Daniel Fernandes Castanheira

\title{
O lugar público de Agrippino. \\ Trânsito e espacialidade na cidade-qualquer
}

Dissertação de Mestrado

Dissertação apresentada como requisito parcial para obtenção do grau de Mestre pelo Programa de Pós-Graduação em Letras do Departamento de Letras da PUC-Rio.

Orientador: Prof. Júlio César Valadão Diniz 
Daniel Fernandes Castanheira

O lugar público de Agrippino. Trânsito e espacialidade na cidade-qualquer

\begin{abstract}
Dissertação apresentada como requisito parcial para obtenção do grau de Mestre pelo Programa de Pós-Graduação em Letras do Departamento de Letras do Centro de Teologia e Ciências Humanas da PUC-Rio. Aprovada pela Comissão Examinadora abaixo assinada.
\end{abstract}

Prof. Júlio César Valadão Diniz Orientador Departamento de Letras - PUC-Rio

Prof. Roberto Correa dos Santos Departamento de História da Arte Instituto de Artes UERJ

Prof. Ericson Siqueira Pires Departamento de Linguagens Artísticas Instituto de Artes

UERJ

Prof. Paulo Fernando C. de Andrade Coordenador Setorial do Centro de Teologia e Ciências Humanas

Rio de Janeiro, 15 de abril de 2009. 
Todos os direitos reservados. É proibida a reprodução total ou parcial do trabalho sem autorização da universidade, da autora e do orientador.

\section{Daniel Fernandes Castanheira}

Daniel Castanheira é Bacharel e Licenciado em Filosofia, com monografia em Filosofia da História pela PUC-Rio(2004); mestre em Literatura pelo departamento de Letras da PUC-Rio (2009), bolsista do CNPQ; desde 1998 é músico, artista sonoro, membro do coletivo de arte Hapax, ligado a performances e apresentações em geral, tanto em música popular como em teatro, cinema e no circuito de artes plásticas; atualmente é professor do Instituto de Artes (DLA) da UERJ (Universidade Estadual do Rio de Janeiro).

Ficha Catalográfica

Castanheira, Daniel Fernandes

O lugar público de Agrippino. Trânsito e espacialidade na cidade-qualquer. / Daniel Fernandes Castanheira; orientador: Júlio César Valadão Diniz. - 2009.

90 f. : il. (PB.) ; $30 \mathrm{~cm}$

Dissertação (Mestrado em Letras)-Pontifícia Universidade Católica do Rio de Janeiro, Janeiro, Departamento de Letras.

Inclui referências bibliográficas.

1. Letras - Teses. 2. José Agrippino 3. Espaço. 4. Polifonia. 5. Mônada. 6. Trânsito. 7. Cidade. 8. Lugar Público. 9. Osvaldo Lamborghini. I. Diniz, Júlio César Valadão. II. Pontifícia Universidade Católica do Rio de Janeiro. Departamento de Letras. III. Título.

CDD: 400 


\section{Agradecimentos}

Ao meu orientador Prof. Júlio Diniz, pela confiança irrestrita e o apoio total.

Ao CNPq e à PUC-Rio, pelos auxílios concedidos, sem os quais esse trabalho não poderia ser realizado.

À CAPES, pelo auxílio concedido para o intercâmbio na Universidad Nacional de Rosario, Argentina, de março a junho de 2008.

Aos meus companheiros do Hapax, Ericson Pires e Ricardo Cutz, por proporcionarem vivências explosivas ao longo dos últimos sete anos .

A todos os interlocutores que participaram e encorajaram o desenvolvimento desta dissertação, em especial Luis Andrade, Christian Dutilleux, Miguel Jost, Guga Ferraz, Emiliano Sete e Felipe Abrahão.

Ao Silas, pelo acesso e disponibilidade.

À minha mãe, como à minha família em geral, pelo suporte e pelas produtivas desconfianças; não seria isso o amor?

À Gabi, pela parceria e o carinho incondicional; não seria isso o amor? 


\section{Resumo}

Castanheira, Daniel Fernandes. Diniz, Júlio César Valadão. O lugar público de Agrippino. Trânsito e espacialidade na cidade-qualquer. Rio de Janeiro, 2009. 90p. Dissertação de Mestrado - Departamento de Letras, Pontifícia Universidade Católica do Rio de Janeiro

O trabalho visa a debater noções e dinâmicas do Espaço na proposta de José Agrippino de Paula. Está dividido em três partes: primeiro, uma introdução sobre o interesse pelo tema do Espaço, aliada à apresentação de um manuscrito inédito do autor, seguido de algumas considerações a respeito desse arquivo. Em segundo lugar, uma análise do romance Lugar Público (1965), onde, numa espécie de jogo ambíguo entre topografias urbanas e literárias, trânsito e espacialidade - ao mesmo tempo figurada e estruturada no romance - são atravessados pelas teorias do Espaço de Gilles Deleuze e Felix Guattari. A parte final é composta por fragmentos, que reúnem textos, faixa de áudio e curta-metragem, resultados de experiências práticas e teóricas inspiradas nessa pesquisa.

\section{Palavras-chave:}

José Agrippino; Espaço; Polifonia; Mônada; Trânsito; Cidade; Lugar Público; GPS; Osvaldo Lamborghini. 


\section{Resumé}

Castanheira, Daniel Fernandes. Diniz, Júlio César Valadão. Le lieu publique d'Agrippino. Transit et spatialité dans la ville-n'importelaquelle. Rio de Janeiro, 2009. 90p. MSc. Dissertation - Departamento de Letras, Pontifícia Universidade Católica do Rio de Janeiro.

Le travail a pour but metre en question des notions et des dynamiques de l'Espace chez José Agrippino de Paula. Il est divisé en trois parties: une introduction sur l'intérêt au suject de l'Espace, allié a la presentation d'un manuscrit inédit de l'auteur, suivi des quelques considérations sur cet archive; l'analise du roman Lugar Público (1965), oú, dans un espèce de jeu ambigu entre des topographies urbaines et litéraires, le mouvement et la spacialité - a la fois figurée et structurée dans le roman - sont traversées par les théorie de l'Espace de Gilles Deleuze et Felix Guatarri; une partie finale composée par des fragments qui réunissent des textes, des bandes sonores et un court-métrage, fruits des expériences pratiques et théoriques, inspirées par cette recherche.

\section{Mots Clé:}

José Agrippino; Espace; Poliphonie; Monade; Transit; Ville; Lieu Public; GPS; Osvaldo Lamborghini.. 


\section{Sumário}

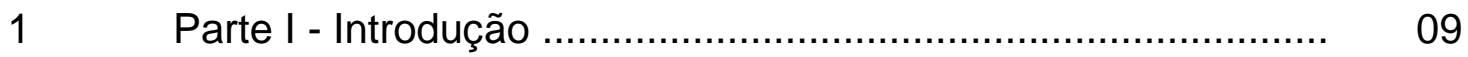

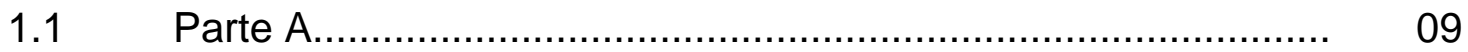

$1.2 \quad$ Parte B - Manuscrito do autor........................................ 15

$1.3 \quad$ Parte C - Crônica............................................................. 24

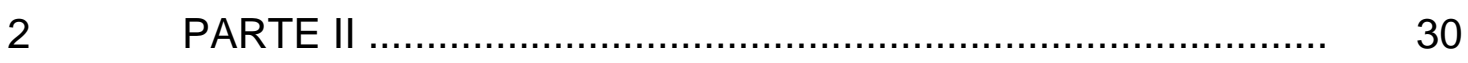

$2.1 \quad$ Parte A - Introdução............................................................. 30

$2.2 \quad$ Parte B - O Romance............................................. 34

2.3 Parte C - Polifonia e topografia........................................ 37

$2.4 \quad$ Parte D - Trânsito e desvio........................................... 43

$2.5 \quad$ Parte E - Espaços ambíguos......................................... 46

3 Parte III - Buracos 49

3.1 Buraco 1 - O movimento forjado em música................................ 50

3.2 Buraco 2 - A vida de Lucas Frizzo. Fabulação dos espaços literários fundidos............................................................ 56

3.2.1 Advertência ................................................................... 57

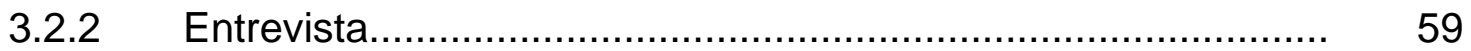

3.3 Buraco 3 - Osvaldo Lamborghini. De l'orto a l'otro; ou vice-

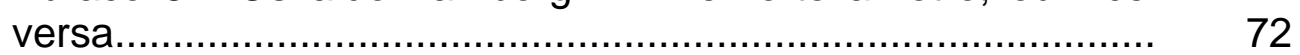

3.3.1 Apresentação.......................................................... $\quad 72$

3.3.2 Esboço acabado............................................... 74

3.3.3 Considerações críticas.............................................. 77

3.3.4 Final esboçado................................................... 80

Considerações Finais............................................. 83

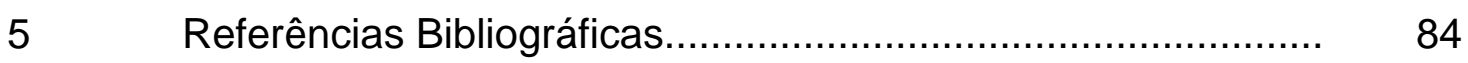

6 Anexo 88 
Um livro de poesia na gaveta não adianta nada

lugar de poesia é na calçada lugar de quadro é na exposição

(Sérgio Sampaio) 